\title{
Extent of gas hydrate filled fracture planes: Implications for in situ methanogenesis and resource potential
}

\author{
Ann E. Cook ${ }^{1}$ and David Goldberg ${ }^{1}$ \\ Received 6 May 2008; revised 24 June 2008; accepted 26 June 2008; published 5 August 2008.
}

[1] High-angle gas hydrate filled fracture planes were identified along a $31 \mathrm{~m}$ interval in logging while drilling images in two holes located $\sim 11 \mathrm{~m}$ apart drilled during the Indian National Gas Hydrate Program Expedition 01, offshore India. Using Monte Carlo simulations to account for uncertainty in hole location, hole deviation, strike and dip, we assert with $95 \%$ confidence that the fracture planes in the two holes are not the same. The gas hydrate filled fracture planes likely only extend a few meters laterally from each borehole and occur in an isolated interval in the middle of the gas hydrate stability zone. This suggests gas generated microbially within in the gas hydrate stability zone may have supplied the gas hydrate-filled fracture interval. Production of methane from these reservoirs using conventional methods may be quite challenging. Citation: Cook, A. E., and D. Goldberg (2008), Extent of gas hydrate filled fracture planes: Implications for in situ methanogenesis and resource potential, Geophys. Res. Lett., 35, L15302, doi:10.1029/2008GL034587.

\section{Introduction}

[2] In the summer of 2006, the Indian National Gas Hydrate Program Expedition 01 (NGHP-01) drilled twenty-one sites on the continental margins of India. The goal of NGHP-01 was to characterize the amount of natural gas hydrate in India as a potential energy resource. Natural gas hydrates are a solid, ice-like material where $\mathrm{H}_{2} \mathrm{O}$ molecules house molecules of natural gas. Natural gas hydrates occur in shallow marine sediments on most of the world's continental margins [Kvenvolden and Barnard, 1983], and may be a significant energy source [Collett, 2002].

[3] NGHP-01 successfully identified gas hydrate at 13 of the 21 sites. Logging-while-drilling (LWD) resistivity images show gas hydrates commonly occurred in clay sediments as fill in high-angle fractures. Pressure cores revealed gas hydrate chiefly formed in a complex structure of fracture planes in clay sediments, effectively confirming the observations from the LWD images [Collett et al., 2008; Holland et al., 2008].

[4] At NGHP-01 Site 5, two LWD holes were drilled, Holes 5A and 5B. Resistivity images from both holes depict high-angle hydrate filled fractures. Also at Site 5, two holes were logged with wireline tools, Holes 5D and 5E, and cores were collected in Holes 5C and 5D (Figure 1). Site 5 is located in the Krishna-Godavari basin on the eastern coast of India in at a water depth of $945 \mathrm{~m}$. Lithology is

\footnotetext{
${ }^{1}$ Borehole Research Group, Lamont-Doherty Earth Observatory of Columbia University, Palisades, New York, USA.
}

Copyright 2008 by the American Geophysical Union. 0094-8276/08/2008GL034587\$05.00 dominated by clay sediment with minor amounts of silt. The thermodynamic base of the gas hydrate stability zone (HSZ) occurs at 130 meters below seafloor (mbsf). Gas hydrate was recovered from Holes $5 \mathrm{C}$ and $5 \mathrm{D}$ and was inferred from the logs in Holes 5A, 5B, 5D and 5E [Collett et al., 2008].

[5] Holes 5A and 5B are $\sim 11 \mathrm{~m}$ apart and were drilled to a total depth of 200 mbsf. Strikingly similar log responses and resistivity images were recorded in Hole $5 \mathrm{~A}$ and Hole 5B. Additionally, the strike and dip of the fractures in Holes $5 \mathrm{~A}$ and $5 \mathrm{~B}$ cluster about $\mathrm{N} 42 \mathrm{~W}, 77 \mathrm{SW}$ (Figure 2). The similarities in the logging curves and the strike and dip data for each hole suggests that fracture planes could be continuous features between these closely spaced holes. The continuity of the fracture planes has implications for the distribution of gas hydrate beyond the borehole wall and provides important information about the potential producibility of such gas hydrate reservoirs.

\section{Log and Image Analysis in Hydrate-Bearing Intervals}

\subsection{Log Analysis}

[6] Natural gas hydrate is an electrical insulator that increases the bulk resistivity of a sediment system. To identify hydrate-bearing intervals (HBI) in Holes 5A and $5 \mathrm{~B}$, we calculate the resistivity of the sediment when gas hydrate is not present in the pore space, $R_{o}$, and compare it to the measured in situ resistivity, $R_{t} . R_{o}$ is defined as $R_{o}=$ $a R_{w} / \phi^{m}$ [Archie, 1942]. The resistivity of the pore water, $R_{w}$, is calculated using the salinity and downhole temperature. Density porosity, $\phi$, is calculated using the measured in situ density from logs, the grain density from the cores at Site 5, and the density of the pore water. The values $a$ and $m$ are determined by selecting sections of the hole that are fully water-saturated, specifically, sections with good hole conditions and low resistivity responses, then matching $R_{o}$ to $R_{t}$. In Holes $5 \mathrm{~A}$ and $5 \mathrm{~B}$ the intervals $40-50 \mathrm{mbsf}$ and 120-180 mbsf were selected as water-saturated to calculate $a$ and $m$.

[7] Figure 2 displays the measured ring resistivity $\left(R_{t}\right)$ and the calculated $R_{o}$ for Holes $5 \mathrm{~A}$ and $5 \mathrm{~B}$. Intervals where the two curves diverge indicate the sediments are hydratebearing. In Hole 5A, the HBI appears from 56 to 94 mbsf. In Hole 5B, the HBI extends from 56 to 90 mbsf.

[8] A similar technique was used to identify HBIs in Holes 5D and 5E. Hole geometry in both Holes 5D and 5E was considerably enlarged, reducing the reliability of the density log values. Because accurate density values are needed to calculate $R_{o}$, an average density curve from Holes $5 \mathrm{~A}$ and $5 \mathrm{~B}$ was used in Holes 5D and 5E. Average values of $a$ and $m$ from Holes 5A and 5B were also applied. Figure 2 


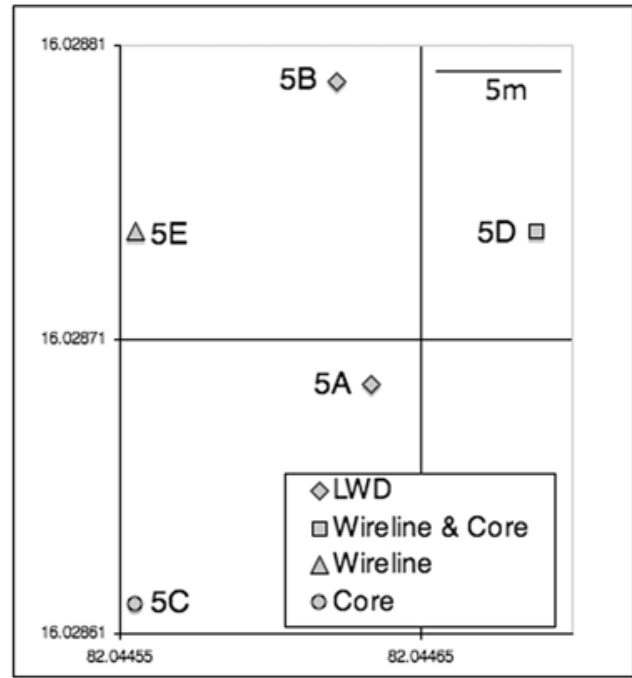

Figure 1. Map of the five holes drilled at Site 5.

illustrates the HBI in Holes 5D and 5E. In Hole 5D, the HBI extends from 75-112 mbsf, quite different from the other holes at Site 5. In Hole 5E, the HBI is almost identical to Hole 5A; the base of the HBI in both holes is 94 mbsf. All HBIs at Site 5 fall well within the thermodynamic HSZ.

\subsection{Image Analysis}

[9] LWD resistivity images from Holes 5A and 5B depict high-angle hydrate filled fractures within the HBIs. Fractures appear as a sinusoid on an oriented resistivity image, which allows for its dip and dip direction (perpendicular to strike) to be calculated. A majority of fractures in Holes $5 \mathrm{~A}$ and $5 \mathrm{~B}$ occur from $60-91 \mathrm{mbsf}$. Fractures dip between $62^{\circ}$ and $88^{\circ}$ towards the southwest, with an average strike of $\mathrm{N}$
$42 \mathrm{~W}$. One fracture appears outside of the HBI occurs at 54 mbsf in Hole 5A; no other fractures, conductive or resistive, occur outside of the HBIs.

[10] While the fracture sets in Holes $5 \mathrm{~A}$ and $5 \mathrm{~B}$ are similar, there are clear differences. The fractures in Hole 5B have, on average, higher dip angle than those in Hole 5A. A larger number of fractures were identified in Hole 5A with a greater degree of strike variation than Hole 5B. These differences may be due to slight reorientation of a fracture plane as it propagates through the sediment. If a fracture plane only partially intersects a borehole or if multiple fractures intersect at a certain depth, individual fractures may be difficult to resolve from the resistivity image. These effects or other tool measurement errors may contribute to the difference in fracture numbers and attributes resolved in each hole.

\section{Fracture Continuity}

[11] Mapping fracture planes between Hole 5A and Hole $5 \mathrm{~B}$ is a simple exercise. Consider the average strike plane $\mathrm{N}$ $42 \mathrm{~W}$ and the average dip of $77 \mathrm{SW}$ cutting through Figure 1. Clearly Hole 5A is downdip from Hole 5B. Using trigonometry, the fractured HBI in Hole 5B, from 60-91 mbsf would then appear $28 \mathrm{~m}$ deeper in Hole 5A, from $88-$ 119 mbsf. However, the HBI in Hole 5A containing the gas hydrate filled fractures occurs from 60-91 mbsf, which suggests that the fracture planes in Hole 5A are not the same fracture planes in Hole 5B.

\subsection{Uncertainty}

[12] The simple exercise does not incorporate many sources of uncertainty such as: the precise location of each hole on the seafloor, the deviation of the borehole, and the effect of image resolution on strike and dip.

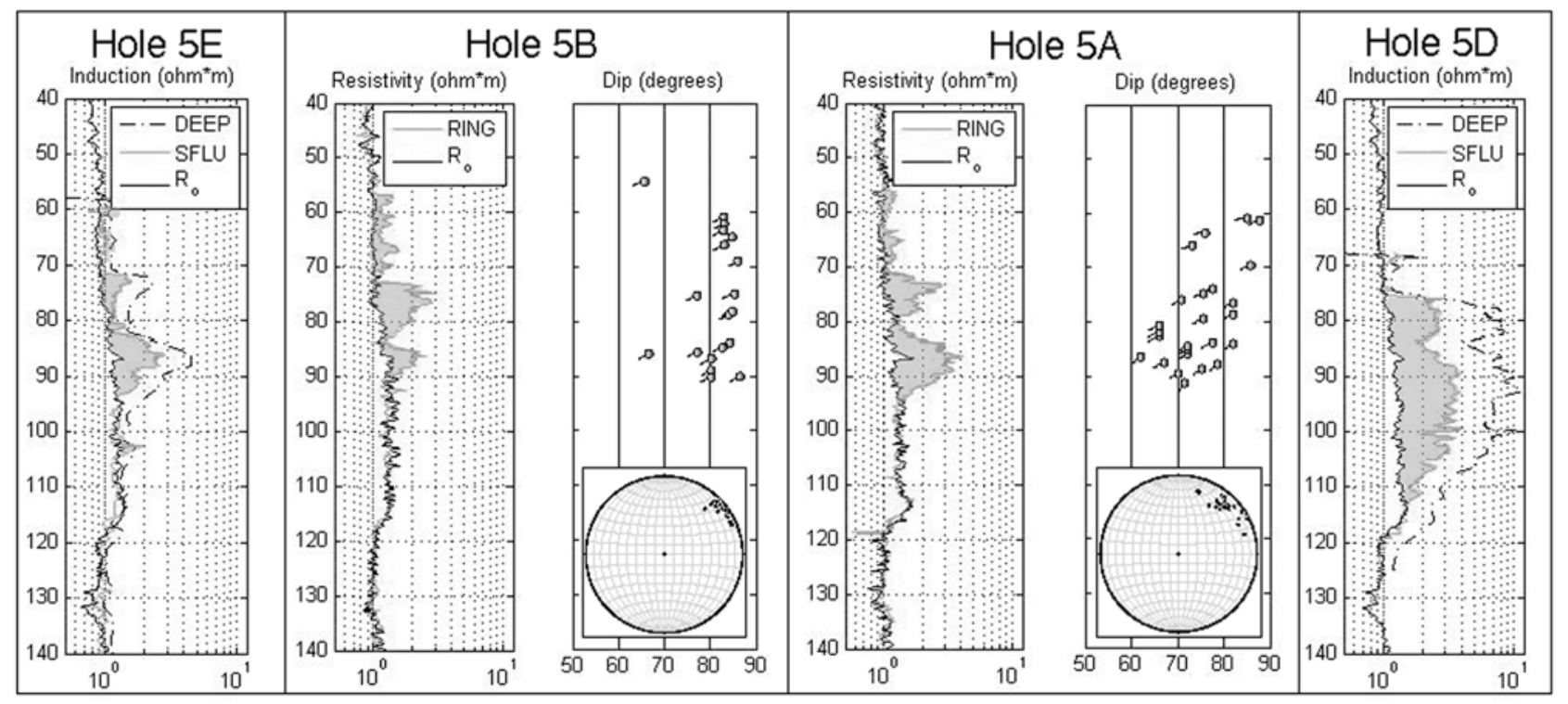

Figure 2. Resistivity curves from Holes 5E, 5B, 5A and 5D. The measured ring resistivity (RING) and spherically focused resistivity (SFLU) are plotted in gray, deep induction resistivity (DEEP) as a dashed line, and $R_{o}$ in black. The HBIs are highlighted in gray. The gas hydrates filled fractures are shown to the right of the resistivity measurement for Hole $5 \mathrm{~A}$ and Hole 5B. The dip is indicated by the dot, and the dip direction by the tail. A lower hemisphere equal area stereonet displaying the poles to each fracture plane appears in the inset for Holes 5A and 5B. 


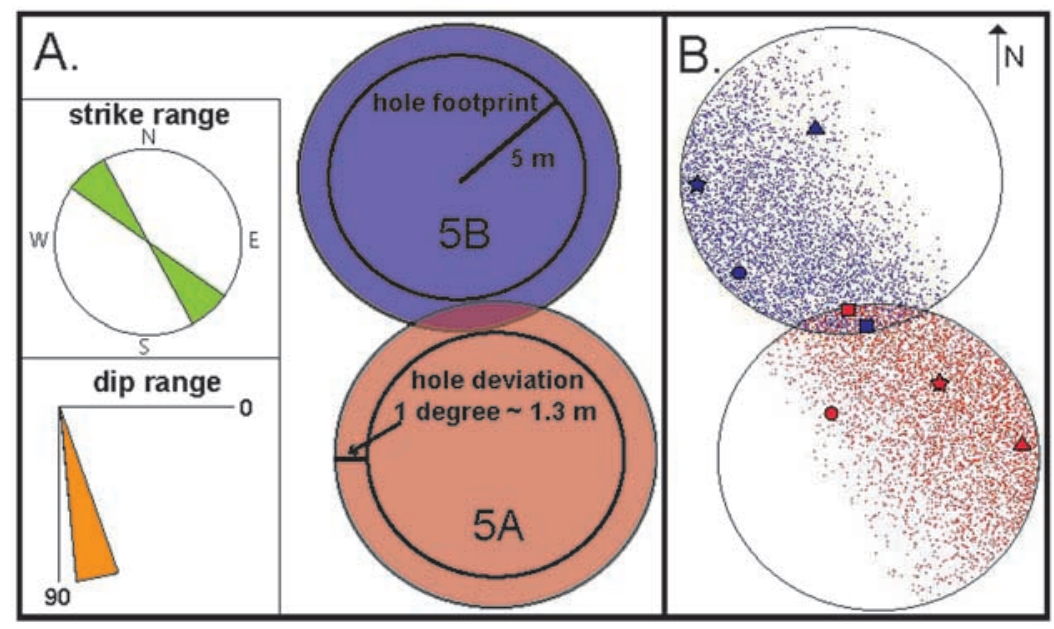

Figure 3. (a) Monte Carlo simulation uncertainty. (b) Matches from a Monte Carlo simulation with a hole footprint of $5 \mathrm{~m}$. Each dot represents a match between the two holes, and each symbol pair represents a specific match.

[13] Global positioning system (GPS) measurements record continuously on the JOIDES Resolution during drilling of a hole, and a mean value is used to determine hole location at the seafloor [Collett et al., 2008]. Differences between the GPS measurement recorded on the ship and the location of the hole on the seafloor likely accrue from small lateral movements of the drill pipe as it spans the ocean depth. Additional error may occur from movement of the ship during GPS measurements. The sum of these uncertainties is poorly known. We ran a Monte Carlo simulation considering a radii of uncertainty, or hole footprint, of $2.5 \mathrm{~m}$, $5 \mathrm{~m}, 10 \mathrm{~m}$ and $50 \mathrm{~m}$ for each Holes 5A and 5B (Figure 3).

[14] Hole deviation, the inclination of a borehole from vertical, was not measured in LWD holes during NGHP-01. In general, LWD holes are assumed to be near vertical; hole stabilizers are used to promote vertical drilling. For the Monte Carlo simulation, we assume a maximum hole deviation of $1^{\circ}$ in Holes 5A and 5B. This effectively adds $1.3 \mathrm{~m}$ to the hole footprint (Figure 3 ) and less than $1^{\circ}$ additional uncertainty to the dip measurement.

[15] Resistivity image resolution also contributes to the strike and dip uncertainty, approximately $6^{\circ}$ and $1^{\circ}$, respectively. Accounting for the variance of each uncertainty, as well as for the variance of the collected strike and dip data, we use the strike range of $\mathrm{N} 54.5 \mathrm{~W}$ to $\mathrm{N} 28.5 \mathrm{~W}$ and dip range of $70.7^{\circ}$ to $84.6^{\circ}$ for the Monte Carlo simulation (Figure 3).

\subsection{Monte Carlo Results}

[16] Monte Carlo simulations were run for 100,000 iterations to evaluate the uncertainty for hole location, hole deviation, strike, and dip on fracture continuity. We define a "match" in the simulation when the fracture zone in Hole 5B, from 60-91 mbsf, occurs anywhere between 57-94 mbsf in Hole 5A. This effectively adds a tolerance of $\pm 3 \mathrm{~m}$ to the fracture continuity test. Table 1 shows the results of the Monte Carlo simulations testing fracture continuity between Hole 5A and Hole 5B for different radii of hole footprints. For any reasonable hole footprint, we assert with $95 \%$ confidence that the gas hydrate filled fracture planes in Hole 5A are not the same fracture planes in Hole 5B.

\section{Discussion}

\subsection{Strike Effect}

[17] The few Monte Carlo iterations (5\% or less) when the fracture planes in Hole 5B match with the fracture planes in Hole 5A depends exclusively on whether or not the hole locations appear on, or very close to strike. Figure 3 depicts all of the 4812 match iterations for a hole footprint of $5 \mathrm{~m}$. Four specific matches between holes are highlighted with large symbols, illustrating the close-to-strike hole location of each match. The significant white section of each footprint contains no matches because the opposing hole's footprint does not extend far enough to accommodate matches on strike.

[18] Hole footprint coupled with strike can explain the small variations in percent of matches reflected in Table 1. With a hole footprint of $2.5 \mathrm{~m}$, the size of the footprint constrains the range of strikes where a match can occur to $\mathrm{N}$ $49.6 \mathrm{~W}$ to $\mathrm{N} 28.5 \mathrm{~W}$, simply because the hole footprints are not large enough to accommodate two locations on strike outside these orientations. With an increased hole footprint of $5 \mathrm{~m}$, the full range of strikes can occur, increasing the chance of a match, however, because the footprints for Hole $5 \mathrm{~A}$ and Hole 5B are oriented approximately N-S a predominance of N-S tending rather than E-W tending matches results. With a hole footprint of $10 \mathrm{~m}$, the range of strikes where a match can occur is evenly distributed due to a $40 \%$ footprint overlap between Hole 5A and 5B. With a hole footprint is $50 \mathrm{~m}$, the overlap between the two holes

Table 1. Results From Monte Carlo Fracture Continuity Simulation

\begin{tabular}{cc}
\hline Hole Footprint, Meters & Matches, Percent \\
\hline 2.5 & 1.9 \\
5 & 4.8 \\
10 & 5.3 \\
50 & 2.3 \\
\hline
\end{tabular}


expands to over $85 \%$ of each hole footprint, vastly increasing the possibility that the hole locations for any given iteration will be off strike and lowering the number of possible matches.

\subsection{Three-Hole Fracture Continuity}

[19] Hole 5E resistivity curves are comparable to Holes $5 \mathrm{~A}$ and $5 \mathrm{~B}$, suggesting that the hydrate show in Hole $5 \mathrm{E}$ is controlled by a similar fracture system. Is it possible that Hole 5E intersects the same fracture planes as Holes 5A and $5 \mathrm{~B}$ ? We adjusted the Monte Carlo simulation to test this possibility using the same strike and dip data from Holes $5 \mathrm{~A}$ and $5 \mathrm{~B}$.

[20] For a match to occur between these three holes, the fractures in Hole 5B (60-91 mbsf) must appear in Holes 5A and $5 \mathrm{E}$ between 57 and 94 mbsf. With a hole footprint of $2.5 \mathrm{~m}$, it is impossible within the bounds of the Monte Carlo simulation for the fracture planes to be continuous through all three holes. Hole $5 \mathrm{E}$ is beyond the range of strike possible for a match. With a hole footprint of $5 \mathrm{~m}$, the match rate is only $0.3 \%$ of Monte Carlo iterations. Fracture planes in Holes 5B and 5E will only match if both hole locations occur in the small area of overlap $(\sim 5 \%$ of footprint size). Additionally, the location of Hole 5A must occur on strike with the overlap area of Holes 5B and 5E. With a hole footprint of $10 \mathrm{~m}$, a match happens in $0.2 \%$ of the iterations. With a $50 \mathrm{~m}$ hole footprint, the percent of matches falls further by two orders of magnitude, due to the extremely low probability of three holes falling on strike in a large unconstrained area. These simulations reiterate the importance of strike to achieve a fracture plane match and the low probability that the fracture planes are continuous between holes.

\subsection{Localized Fracturing}

[21] The observation that gas hydrate zones occur in three closely spaced holes at nominally equal depths could be explained if the gas hydrate resides in the pore space of horizontal bedding layers that appear between 56-94 mbsf. But, we know from resistivity images and pressure cores that gas hydrate fills high-angle fractures and not horizontal beds. Fractures do seem to preferentially occur from $\sim 56-$ 94 mbsf. However, no specific lithologic change in the logs corresponds to the to the fracture interval in any hole at Site 5. Additionally, cores from Hole 5C and 5D suggest the geology from seafloor to $200 \mathrm{mbsf}$ is one lithological unit, composed primarily of clay with some silt beds [Collett et al., 2008]. If fracturing is controlled by a lithology change in the HBI, no supporting evidence is found in the logs or cores.

[22] We revisited the Monte Carlo results to determine the likelihood that a fracture in Hole 5B should occur anywhere in Hole 5A. For example, with a $5 \mathrm{~m}$ hole footprint, $99 \%$ of iterations imply a fracture plane from Hole 5B should occur somewhere between 0 and $200 \mathrm{mbsf}$ in Hole 5A, but, no fractures are observed aside from those shown in Figure 2 appear in either hole. For hole footprints of $2.5 \mathrm{~m}$ and $10 \mathrm{~m}$ the results show comparably high fracture appearance between holes, $100 \%$ and $95 \%$ respectively. Only with a $50 \mathrm{~m}$ hole footprint does instance of a fracture plane intersecting anywhere in both holes significantly drop to $46 \%$. Still, this suggests fracture planes are not continuous features that extend between holes. Additionally, there is no evidence fracture planes extend to the base of the HSZ. Instead, the observed fractures planes appear to be localized features, spanning only a few meters.

[23] We cannot determine if fracture planes intersect beyond the boreholes drilled at NGHP-01 Site 5, but if gas hydrate-filled fractures are indeed small and locally discrete planes, as they appear to be, the proposed methods of gas production through fractures in non-permeable sediments must evolve significantly to extract methane from this environment.

\subsection{Methane Source}

[24] The origin of the methane gas sequestered in gas hydrates can be a deep thermogenic source or a microbial source. At Site 5, we exclude the thermogenic source because headspaces analysis of hydrocarbon gasses from Hole 5C and Hole 5D indicate gas of a microbial origin [Collett et al., 2008]. Microbes present in the HSZ likely generated the methane within the HBI which gave rise to the gas hydrate-filled fractures. Microbial methanogenesis begins below the SMI, or sulfate-methane interface [Claypool and Kaplan, 1974; Borowski et al., 1999]. The SMI at Site 5 appears at 24 mbsf in Hole 5C and $11.5 \mathrm{mbsf}$ in Hole 5D [Collett et al., 2008]. Below the SMI depths, microbes generate methane from the breakdown of organic carbon and the methane is dissolved into the pore water. Over time, the dissolved methane in the pore water increases and sedimentation at the seafloor continues, effectively moving the pore water, sediment, and organic matter deeper into the HSZ. When the amount of microbial generated methane exceeds solubility, gas hydrate forms in lenses outside of the small restrictive pore throats of clay sediments [Clennell et al., 1999, Tohidi et al., 2001]. The actual growth of gas hydrate in clay sediment is poorly understood. In clay-dominated shallow marine sediments, gas hydrate eventually forms in pore-segregated fracture planes that propagate in the direction of the maximum principal stress (in this case, nearly vertical) [Clennell et al., 1999]. Comparable rates of microbial methane generation may therefore induce shallow fracturing in clay sediments at similar depths when in situ properties, stress and lithologies remain alike, such as Hole 5A and Hole 5B.

[25] This scenario could also occur if the microbial gas was generated below the HSZ. Microbial gas could be generated at depths as deep as 800 mbsf [D'Hondt et al., 2004] and slowly advect in a vertical direction through the sediments in the aqueous phase. Recycling of gas once sequestered in hydrates and dissociated below the HSZ could increase the amount of gas in aqueous flow [Paull et al., 1994]. However, if the gas exceeded solubility, the clay sediments must fracture to accommodate gas hydrate formation, as described above. For this reason, we believe gas only achieves saturation in the HBI, otherwise, fracturing would be visible in the sediments between 95 and 200 mbsf in Holes 5A and 5B.

[26] The clay fracturing is seen in the pressure cores recovered from several NGHP-01 sites. The $\mathrm{x}$-ray imaged pressure cores depict gas hydrate residing predominately in fracture planes and veins, which are often near vertical. Additionally, gas hydrate sometimes appears in horizontal 
planes and nodules, and a small amount of gas hydrate is disseminated in pore space [Collett et al., 2008].

[27] The pressure cores from Hole 5D estimate gas hydrate saturation between $5.4-8.0 \%$ at $77 \mathrm{mbsf}, 9.4 \%$ at $85 \mathrm{mbsf}$ (in the HBI), and less than one percent at 115 and 125 mbsf (below the HBI) [Collett et al., 2008]. Considering the higher resistivity measurements in Hole 5D, the bulk hydrate saturations from Hole 5D are likely on the high end for saturations from Site 5. Hydrate saturations from the pressure cores are comparable to those calculated by Claypool et al. [2006], which were attributed to microbial sources within the HSZ near Hydrate Ridge, offshore Oregon. Hole 5D saturations are slightly larger than the few percent gas hydrate saturation calculated by Paull et al. [1994] and Davie and Buffett [2003] for methane generated in the HSZ on Blake Ridge, offshore South Carolina. However, Paull et al. and Davie and Buffett predict the highest methane concentration directly above the base of the HSZ, not in an isolated HBI unconnected to the base of hydrate stability. Liu and Flemings [2007] predicted fracturing within the HSZ due to gas pressure build up behind an impermeable gas hydrate seal. However, this scenario assumes enough gas to form a buoyant, separate gas phase, much more than is likely present at Site 5. Additionally, no indications of free gas are visible in the resistivity images or in the neutron porosity/density-porosity log data collected at Site 5. If microbial gas is transported from below the HSZ, it is likely a small amount in aqueous flow, otherwise gas hydrate would appear near the base of stability, and indications of gas would be present below the gas hydrate zone on the images and logs. Microbial gas generated solely in the HSZ, or the addition of a small amount of gas advected from below the HSZ, appear to be the most likely methane sources at Site 5 .

\section{Conclusions}

[28] Using a Monte Carlo simulation accounting for uncertainty in hole location, hole deviation, strike, and dip we show gas hydrate-filled fracture planes at Site 5 do not appear to be continuous, extensive features. Gas hydratefilled fracture planes at Site 5 likely only extend a few meters and are not continuous between holes. Because the gas hydrate filled fractures appear almost exclusively in a hydrate-bearing interval unconnected to the base of the gas hydrate stability zone we suggest the small planar fractures may be generated by gas formed locally by microbes. This proposed gas hydrate system may appear in many shallow clay-dominated marine sediments. Gas sequestered in small hydrate-filled fracture planes present a significant challenge for resource production.

[29] Acknowledgments. We thank the Directorate General of Hydrocarbons in India and the Ministry of Petroleum in India for allowing the use of data collected during the National Gas Hydrate Program Expedition 01 (NGHP-01). We greatly appreciate the efforts of the co-chiefs, crew, staff, and science party of the JOIDES Resolution during NGHP-01. We also thank Alberto Malinverno, William B.F. Ryan and George Claypool for their comments and suggestions on this paper.

\section{References}

Archie, G. E. (1942), The electrical resistivity log as an aid in determining some reservoir characteristics, Trans. Am. Inst. Min. Metall. Pet. Eng., 146, 54-62.

Borowski, W. S., C. K. Paull, and W. Ussler (1999), Global and local variations of interstitial sulfate gradients in deep-water, continental margin sediments: Sensitivity to underlying methane and gas hydrates, Mar Geol., 159(1-4), 131-154, doi:10.1016/S0025-3227(99)00004-3.

Claypool, G. E., and I. R. Kaplan (1974), The origin and distribution of methane in marine sediments, in Natural Gases in Marine Sediments, edited by I. R. Kaplan, pp. 99-139, Plenum, New York.

Claypool, G. E., et al. (2006), Microbial methane generation and gas transport in shallow sediments of an accretionary complex, Southern Hydrate Ridge (ODP Leg 204) offshore Oregon, USA, edited by A. M. Trehu et al., Proc. Ocean Drill. Program Sci. Results, 204, 52 pp.

Clennell, M. B., M. Hovland, J. S. Booth, P. Henry, and W. J. Winters (1999), Formation of natural gas hydrates in marine sediments: 1 . Conceptual model of gas hydrate growth conditioned by host sediment properties, J. Geophys. Res., 104(B10), 22,985-23,004.

Collett, T. S. (2002), Energy resource potential of natural gas hydrates, AAPG Bull., 86(11), 1971 - 1992, doi:10.1306/61EEDDD2-173E-11D7$8645000102 \mathrm{C} 1865 \mathrm{D}$

Collett, T. S., et al. (2008), Results of the Indian National Gas Hydrate Program Expedition 01 initial reports, report, Dir. Gen. of Hydrocarbons, Min. of Pet. and Nat. Gas, New Delhi.

Davie, M. K., and B. A. Buffett (2003), Sources of methane for marine gas hydrate: inferences from a comparison of observations and numerical models, Earth Planet. Sci. Lett., 206(1-2), 51-63, doi:10.1016/S0012821X(02)01064-6.

D'Hondt, S., et al. (2004), Distributions of microbial activities in deep subseafloor sediments, Science, 306(5705), 2216-2221, doi:10.1126/ science. 1101155 .

Holland, M., P. Schultheiss, J. Roberts, and M. Druce (2008), Observed gas hydrate morphologies in marine sediments, paper presented at the 6 th International Conference on Gas Hydrates, Vancouver, BC, Canada, 7-10 July.

Kvenvolden, K., and L. Barnard (1983), Hydrates of natural gas in continental margins, AAPG Mem., 34, 631-640.

Liu, X., and P. B. Flemings (2007), Dynamic multiphase flow model of hydrate formation in marine sediments, J. Geophys. Res., 112, B03101, doi:10.1029/2005JB004227.

Paull, C. K., et al. (1994), Sources of biogenic methane to form marine gas hydrates in situ production or upward migration?, Ann. N. Y. Acad. Sci., $715(1), 392-409$

Tohidi, B., et al. (2001), Visual observation of gas-hydrate formation and dissociation in synthetic porous media by means of glass micromodels, Geology, 29(9), 867-870.

A. E. Cook and D. Goldberg, Borehole Research Group, LamontDoherty Earth Observatory of Columbia University, 61 Route 9W, Palisades, NY 10964-8000, USA. (acook@ldeo.columbia.edu; goldberg@ ldeo.columbia.edu) 